\title{
Femur Diafizinde Ewing Sarkom ve Literatür İncelemesi
} Ewing Sarkom in Femur Diaphysis and Literature Review

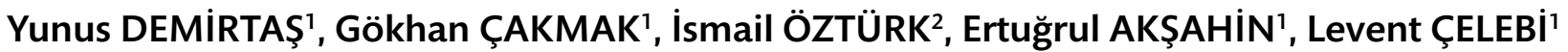 \\ ${ }^{1}$ Yüksek İhtisas Üniversitesi Tıp Fakültesi, Ortopedi ve Travmatoloji Anabilim Dalı, Ankara, Türkiye \\ ${ }^{2}$ Yüksek İhtisas Üniversitesi Sağlık Hizmetleri Meslek Yüksek Okulu, Liv Hospital Hastanesi Anesteziyoloji ve Reanimasyon Kliniği, Ankara, Türkiye
}

öz

Ewing sarkom osteosarkom sonrası ilk iki dekatta en çok gözlenen malign tümörlerden bir tanesidir. Son zamanlardaki sistemik multi-ajan kemoterapi ajanları ile birlikte mortalite oranlarında ve nüks oranlarında belirgin oranda düşüş saptanmıştır. Ewing sarkom genellikle uzun kemiklerin diafizer bölgesini sıklıkla tutmaktadır. Bu bölgedeki kemik rezeksiyonları sonrası kemik defektlerinin tedavisi ile ilgili literatürde birçok yöntem tanımlanmıştır. Hastaların genç yaşta olması biyolojik tedavi seçeneğinin ön planda olması gerekliliğini ortaya koymuştur. Biz de bu vakada femurdaki kemik defektini nonvaskülarize fibular greft ile rekonstrükte ettik.

Anahtar Sözcükler: Ewing sarkom, malign kemik tümörü, kemik defekti

\section{ABSTRACT}

Ewing sarcoma is one of the most common malignant tumors in the first two decades after osteosarcoma. With the recent systemic multiagent chemotherapy agents, there has been a significant decrease in mortality and recurrence rates. Ewing sarcoma usually involves the diaphyseal region of long bones. Many methods have been described in the literature regarding the treatment of bone defects after bone resections in this region. The young age of the patients revealed that the biological treatment option should be at the forefront. In this case, we reconstructed the bone defect in the femur with a non-vascularized fibular graft.

Keywords: Ewing sarcoma, malignant bone tumour, bone defect

Cite this article as: Demirtaş Y, Çakmak G, Öztürk I, Akşahin E, Çelebi, L. Femur Diafizinde Ewing Sarkom ve Literatür Incelemesi. YIU Saglik Bil Derg 2021;2: 23-26.

\section{Giriş}

Malign tümörlerin tedavisindeki son gelişmelere rağmen halen büyük sorunlar bizi beklemektedir. Ewing sarkom çocukluk çağ tümörlerinin \%1'inden azını oluşturur. Bu tümörlerin \%90'1 kemikten, \%10'u kemik dişı yumuşak dokudan kaynaklanırlar. Olguların çoğu 20 yaş altındadır. Bazı olgularda 11-22 translokasyonu gözlenebilir. Patolojik olarak küçük yuvarlak hücreli tümör grubuna dâhil edilirler. Erkeklerde görülme ihtimali kızlara oranla fazladır (1). Biz bu çalışmamızda 11 yasında sol femur diafizinde Ewing sarkom tanısıyla opere ettiğimiz hastayı sunduk.

\section{Olgu Sunumu}

11 yaşında bayan hasta dış merkezde sol uyluk ağrısı nedeniyle gittiği merkezde biyopsi alındığı biyopsi sonucunun Ewing
Sarkom geldiği tespit edildi. Hasta bu tanı ile bize refere edildi. Hastanın yapılan sorgulamasında yaklaşık üç aydır sol uylukta ağrı olduğu, ateşinin ve travma öyküsünün olmadığı tespit edildi. Hastanın ağrılarının özellikle geceleri olduğu ve yürümekle ağrılarının arttığı öğrenildi. Halsizlik şikâyetinin olduğu ancak kilo kaybının olmadığı tespit edildi. Hastaya biyopsi sonrası radyoterapi verilmediği, neoadjuvan olarak üç seans Vinkristin, Adriamisin, Aktinomisin D ve Etopsit protokolü verildiği tespit edildi. Yapılan fizik muayenede sol uyluk orta 1/3'te anteriorda yaklaşık $5 \mathrm{~cm}$ insizyon skarı olduğu tespit edildi. Bu bölgede hiperemi ısı artışı yoktu. Kalça ve diz eklem hareketleri ağrılı ve tam idi. Yapılan nörovasküler muayene doğal idi.

Hastaya çekilen PET-CT'de sol uyluk orta 1/3'te tutulum olduğu diğer organ ve kemiklerde metastaz bulgusu olmadı̆̆ı saptandı.

Correspondence Address/Yazışma Adresi: Dr. Öğr. Üyesi Yunus DEMiRTAŞ, Yüksek îtisas Üniversitesi Tıp Fakültesi, Ortopedi ve Travmatoloji Anabilim Dalı, Ankara, Türkiye E-mail: yunusdemirtas@yiu.edu.tr; Y.D: https://orcid.org/0000-0002-4866-4127, G.Ç: https://orcid.org/0000-0002-7230-2871, i.ö: https://orcid.org/0000-0003-4790-5862, E.A: https://orcid.org/0000-0001-5771-8476, L.Ç: https://orcid.org/0000-0002-6260-5692 
Hastaya çekilen sol uyluk kontrastlı manyetik rezonans (MR) görüntülemede sol uyluk orta $1 / 3$ 'te geçirilmiş operasyona bağl1 kavite, lameller tipte konsantrik periostal reaksiyon olduğu, skip metastaz olmadığı, T1 sekansta yaklaşık 12 mm'lik hipoekoik alan saptandığ1, T2 sekansta yaklaşık $16 \mathrm{~cm}$ 'lik segmente hiperekoik alanların olduğu, bu bölgede kontrast tutulumun olduğu tespit edildi (Şekil 1 ve Şekil 2).

Hasta Ewing sarkom tanısı ile genel anestezi altında operasyona alındı. Sol femur proksimalinden başlayan insizyon uyluk orta hatta doğru biyopsi sınırı da insizyon hattında kalacak şekilde açıldı. Katlar geçildi. Rektus femoris kası biyopsi hattı ve Musculus intermedius kası geniş olarak eksize edildi. Ardından MR ölçümleri göz önüne alınarak proksimal ve distal femurdan

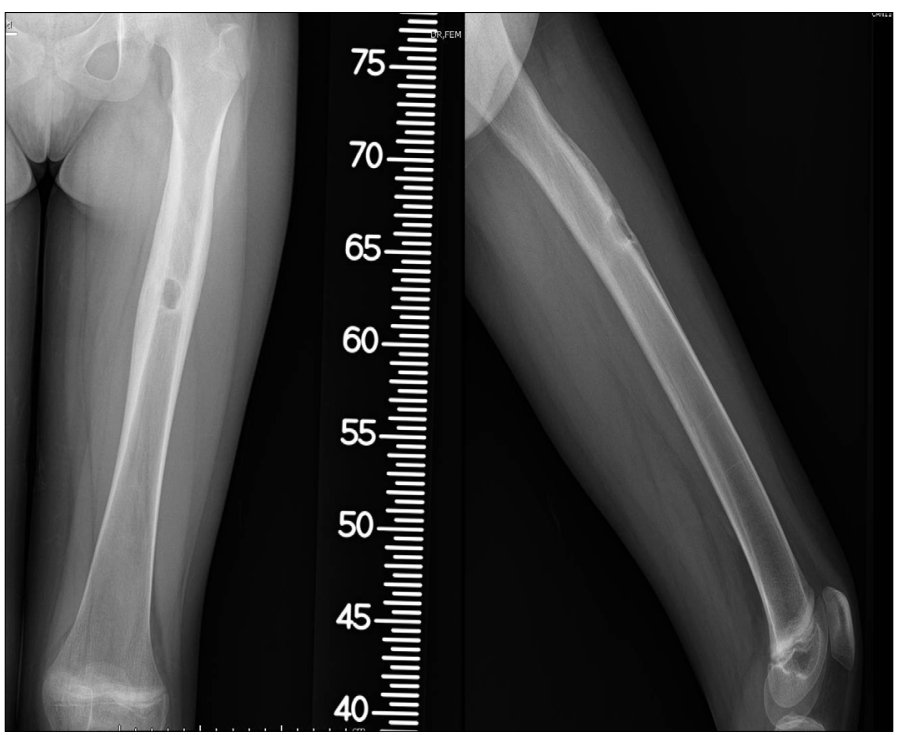

Şekil 1. Hastanın femur ön-arka ve yan grafileri

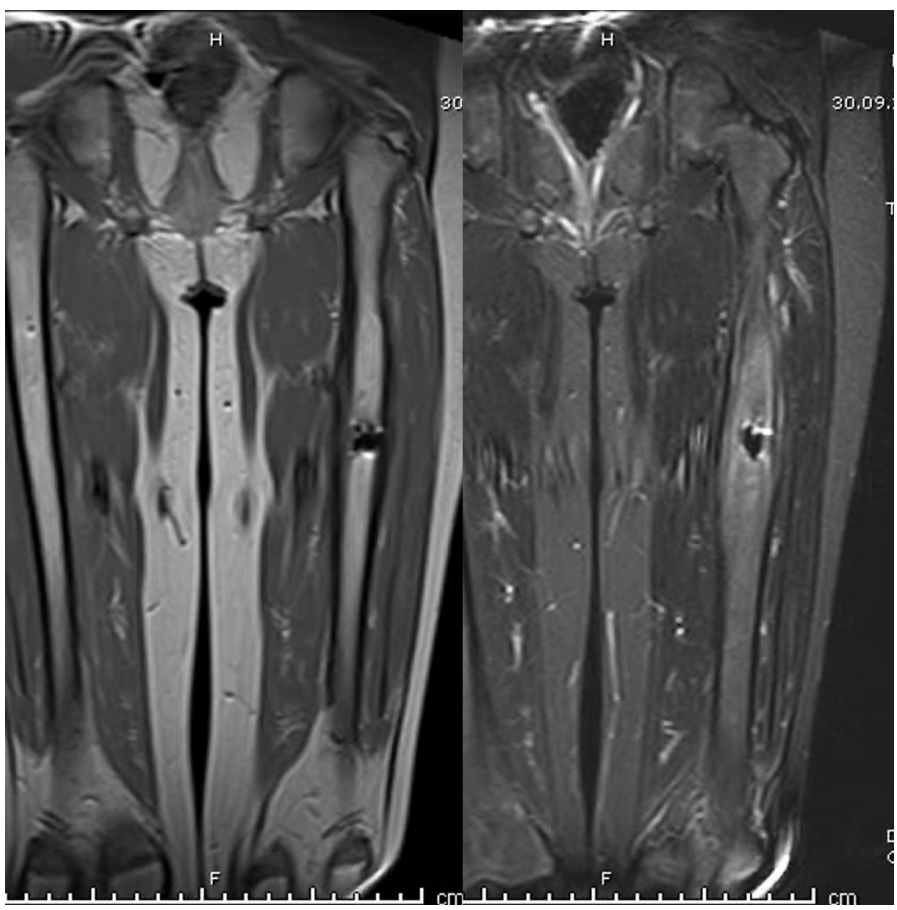

Şekil 2A. Hastanın MR görüntüsü.

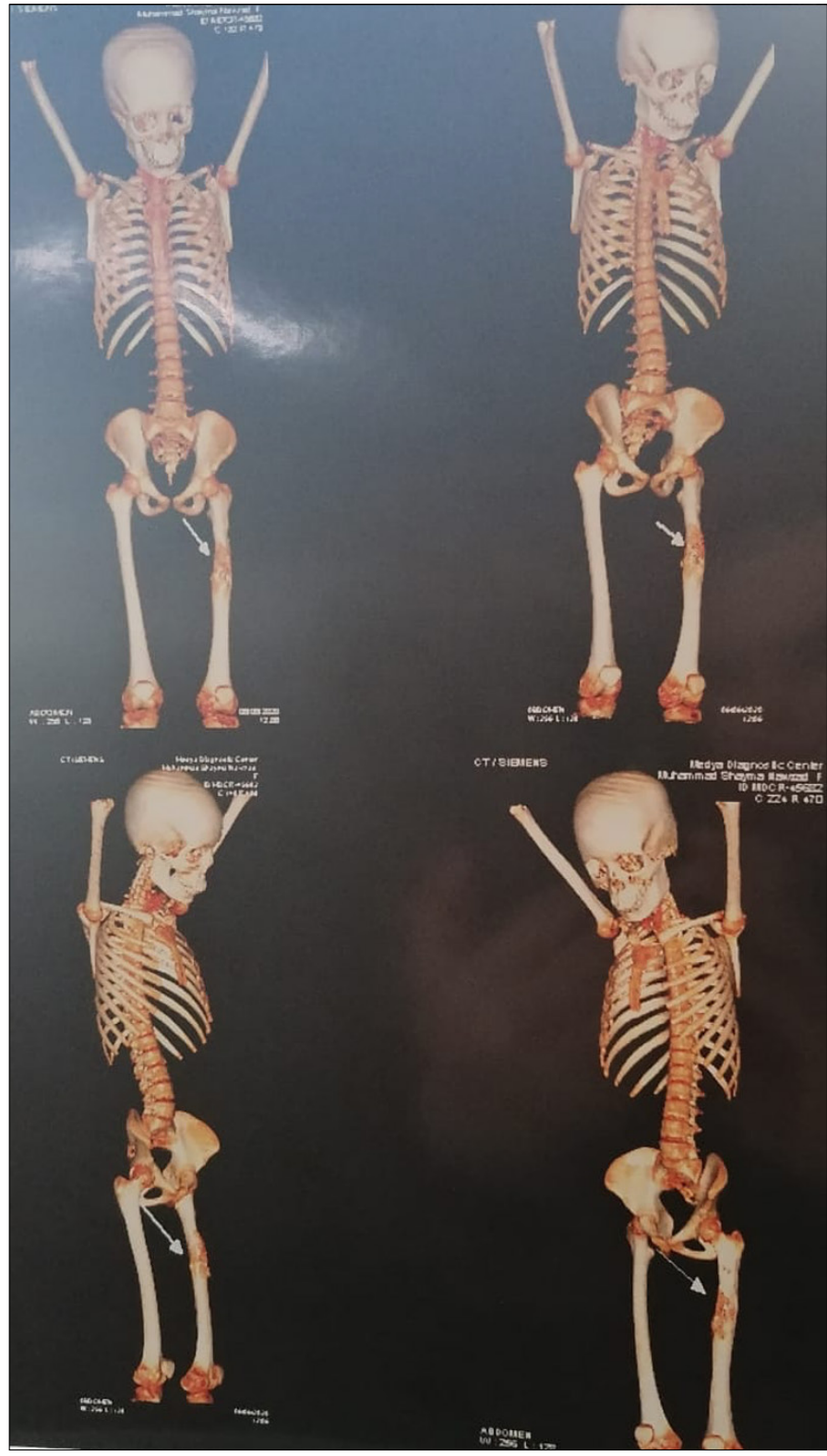

Şekil 2B. Hastanın PET-CT görüntüleri.

cerrahi sınır $2 \mathrm{~cm}$ bırakılarak toplam $20 \mathrm{~cm}$ 'lik alan eksize edildi; patolojiye yolland. Tümör bölgesinden yumuşak dokudan cerrahi sınır için biyopsi alındı. Ardından sağ fibula üzerinden yaklaşık 25 cm'lik insizyonla girildi. Peroneal sinir korundu toplam $22 \mathrm{~cm}$ 'lik nonvaskülerize fibular greft alındı. Sağ ayak bileği instabilitesi yaratmamak için skopi kontrolünde bir adet 3,5 mm'lik kanüllü vida ile epifiz hattı korunarak sindosmoz tespit edildi. Ardindan sol femur proksimal medullası ve distal medullası hazırlanarak fibular greft intramedüller yerleştirildi. Ardından femur proksimal plak ile tespit edildi. Skopi ile kontrol edildi. Diren kondu katlar kapatıldı operasyona son verildi (Şekil 3). Bir hafta sonra patoloji raporu Ewing sarkom cerrahi sınırlar temiz olarak raporlandı.

\section{Tartışma}

Ewing sarkom, osteosarkom sonrası ikinci sıklıkta gözlenen tümördür (1). Sıklıkla femur diafizinde gözlenmekle birlikte 


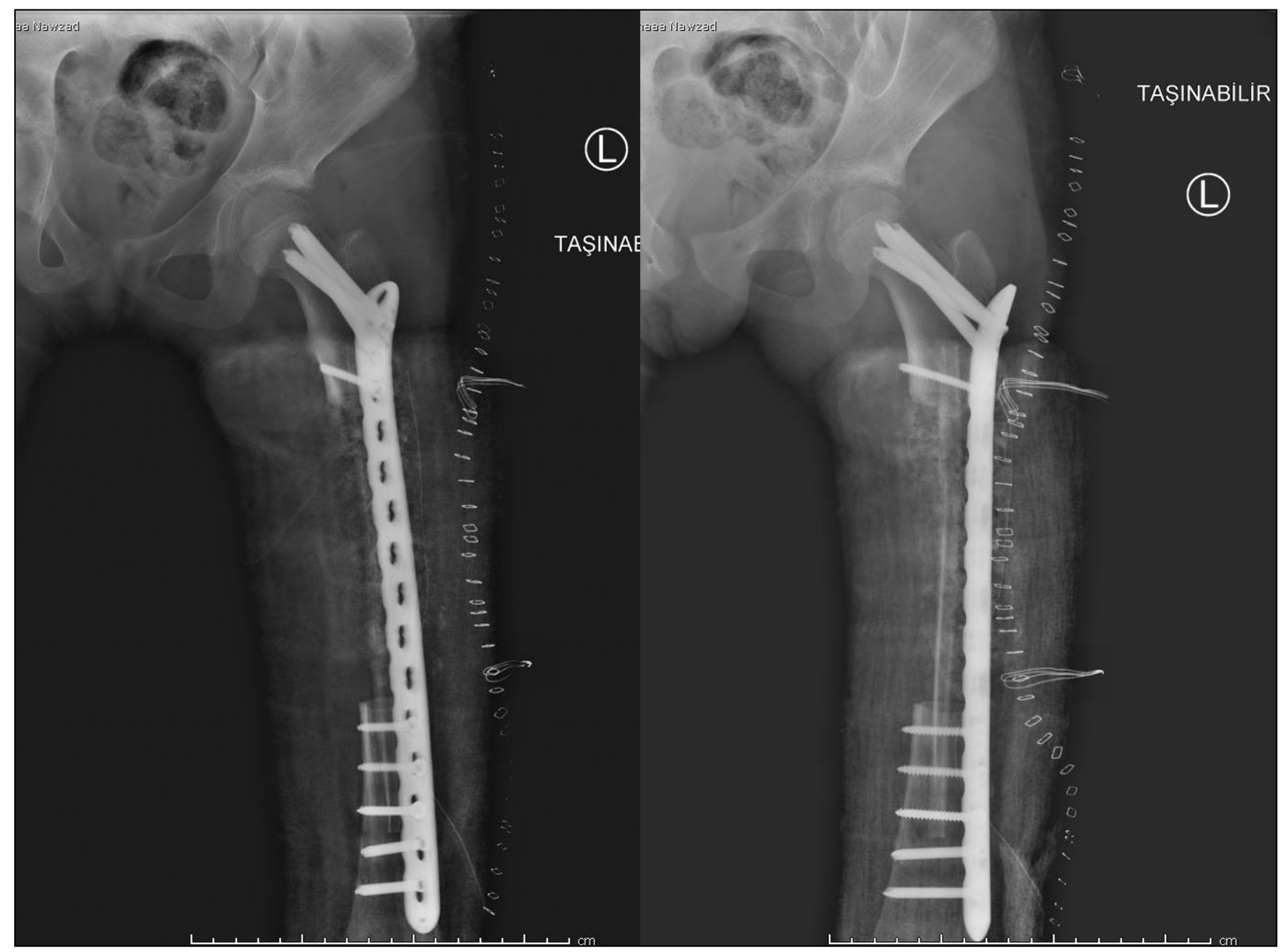

Şekil 3. Olgunun postoperatif görüntüsü.

tüm kemiklerin metafizer ve metafizediafizer bölgesinde ve de yumuşak dokuda gözlenebilmektedir. Sıklıkla hayatın ikinci dekatında gözlenirler ve erkek cinsiyette görülme oranı biraz daha yüksektir (2). Histolojik gelişimi tam açıklanamamakla birlikte kemik iliği endotel hücrelerinden geliştiği düşünülmektedir (3).

Hastalık genelde ağrı, ateş ve palpe edilebilen şişlik bulguları ile karşımıza çıkar. Bunun yanında patolojik kırık daha az sıklıkla gözlenir (4). \%20 oranında hastada uzak metastaz gözlenebilmektedir. Akciğer metastazı olan olgularda ral, ronküs gibi akciğer bulguları gözlenebilmektedir (5).

Hastalığın tanısı öncelikle etkilenen alanın değerlendirilmesi ile başlar. Bu hastalarda tanı anında \%20 metastaz olması nedeniyle sistemik muayene şarttır. İlk değerlendirme röntgenogram olmalıdır. Direkt grafilerde güve-yeniği manzarası, periost reaksiyonuna bağlı Codman üçgeni gözlenebilir. Bunun dışında etkilenen bölgenin MR görüntülerinin elde edilmesi şarttır. Böylelikle yumuşak doku tutulumunun olup olmadığ kemikte ne kadar alanın tutulup tutulmadığı ve de skip metastaz değerlendirilmiş olur. Sistemik yayılımın değerlendirilmesi açısından PET-CT görüntülemesi, akciğer metastazını değerlendirmek açısından toraks tomografisi gereklidir (6). Histolojik değerlendirme açıandan tru-cut biyopsi ya da açık biyopsi gereklidir. Biyopsi yapılacak bölgenin seçimi yapılırken ikincil cerrahi göz önünde bulundurulmalı, cerrahi insizyonu değiştirecek biyopsi noktaları seçilmemelidir. Ayırıcı tanıda osteomyelit, eosinofilik granülom, osteosarkom akılda tutulmalidir (7).
Hastalığın cerrahi tedavisinde büyük kemik defektleri oluşabilmektedir. $\mathrm{Bu}$ defektlerin rekonstrüksiyonunda birçok yöntem tanımlanmıştır. Bunlar; tümör rezeksiyon protezleri, vaskülarize fibular greft, non-vaskülerize fibular greft ve allogreftlerdir. Son zamanlarda tanımlanan Masqulet tekniğine dair olgu sunumları mevcuttur (8-12). Biyolojik rekonstrüksiyonlar hastaların genç olması nedeniyle ve sağ kalımının uzun süre olması nedeniyle daha çok tercih edilmektedir. Allogreftler cerrahi alan enfeksiyonlarının ve maliyetlerinin yüksek olması nedeniyle çok tercih edilmez. Fibular greftlerin ince olması ve dönor saha komplikasyonları nedeniyle handikaplarının olmasına karşın, biyolojik tespit olması ve maliyetlerinin düşük olması nedeniyle avantajları mevcuttur (13). Bizde olgumuzda nonvaskülarize fibular greft tercih ettik.

Ewing sarkom radyoterapi ve kemoterapiye duyarlı bir tümördür. Son zamanlarda multi-ajan tedavilere rağmen beş yıllık sağkalım \%20’lerden \%70'lere çıkmıştır. Standart bir tedavi olmamasına karşın, lokal cerrahi tedaviye ilaveten radyoterapi uygulamaları, metastatik hastalık yoksa tedavide yeterli olmaktadır. Ancak metastatik rahatsılık varsa lokal cerrahi tedaviye ilaveten sistemik kemoterapi ajanları (vincristin, dactinomisin, siklofosfamid, ifosfamid, etoposid) sağ kalımı belirgin oranda uzatmıştır.

Sonuç olarak Ewing sarkom tedavisindeki gelişmeler halen devam etmektedir. $\mathrm{Bu}$ süreçte biyolojik cerrahi tedavi tekniklerinin gelişmesi uzun dönem sağ kalım açısından önemlidir. 
Peer-review: Externally peer-reviewed.

Author Contributions: Concept - YD; Design - YD, GÇ; Supervision - LÇ, EA; Resource - LÇ; Materials - YD; Data Collection and/ or Processing - YD; Analysis and/or Interpretation - YD; Literature Search - YD; Writing - YD; Critical Reviews - EA.

Conflict of Interest: The authors do not have any conflicts of interest.

Financial Disclosure: The authors declared that this study has received no financial support.

Hakem Değerlendirmesi: Dış Bağımsız.

Yazar Katkıları: Fikir - YD; Tasarım - YD, GÇ; Denetleme - LÇ, EA; Kaynaklar - LÇ; Malzemeler- YD; Veri Toplanması ve/veya İşlemesi -YD; Analiz ve/veya Yorum - YD; Literatür Taraması - YD; Yazıyı Yazan - YD; Eleștirel İnceleme - EA

Çıkar Çatışması: Yazarların herhangi bir çıkar çatışması bulunmamaktadır.

Finansal Destek: Yazarlar bu çalışma için finansal destek almadıklarını beyan etmişlerdir

\section{Kaynaklar}

1. Bülbül B, Elli M, Dağdemir A, Dabak N, Acar S, Barış S, et al. Çocukluk Çağı Ewing Sarkomlu Olguların Retrospektif Değerlendirilmesi. J Exp Clin Med 2011;27:66-72. https://doi.org/10.5835/jecm.omu.27.02.007

2. Atalay İ. Prognostic Factors Affecting the Treatment of Ewing Sarcomas; 2008.

3. Enneking WF. Muskuloskeletal Tumor Surgery. EWING's Sarcoma, Volume 2. New York: Churchill Livingstone; 1983; pp.1345-1380.

4. Sluga M, Windhager R, Lang S, Heinzl H, Krepler P, Mittermayer F, et al. A long-term review of the treatment of patients with Ewing's sarcoma in one institution. Eur J Surg Oncol 2001;27:569-573. https://doi.org/10.1053/ ejso.2001.1164
5. Ozaki T. Diagnosis and treatment of Ewing sarcoma of the bone: a review article. J Orthop Sci 2015;20:250-263. https://doi.org/10.1007/s00776-0140687-z

6. Ross KA, Smyth NA, Murawski CD, Kennedy JG. The biology of ewing sarcoma. ISRN Oncol 2013;2013:759725. https://doi.org/10.1155/2013/759725

7. Burchill SA. Ewing's sarcoma: diagnostic, prognostic, and therapeutic implications of molecular abnormalities. J Clin Pathol 2003;56:96-102. https:// doi.org/10.1136/jcp.56.2.96

8. Aldlyami E, Abudu A, Grimer RJ, Carter SR, Tillman RM. Endoprosthetic replacement of diaphyseal bone defects. Long-term results. Int Orthop 2005;29:25-29. https://doi.org/10.1007/s00264-004-0614-6

9. Abudu A, Carter SR, Grimer RJ. The outcome and functional results of diaphyseal endoprostheses after tumour excision. J Bone Joint Surg $\mathrm{Br}$ 1996;78:652-657. https://doi.org/10.1302/0301-620x.78b4.0780652

10. El-Gammal TA, El-Sayed A, Kotb MM. Reconstruction of lower limb bone defects after sarcoma resection in children and adolescents using free vascularized fibular transfer. J Pediatr Orthop B 2003;12:233-243. https:// insights.ovid.com/pubmed?pmid=12821839

11. Hsu RW, Wood MB, Sim FH, Chao EY. Free vascularised fibular grafting for reconstruction after tumour resection. J Bone Joint Surg Br 1997;79:36-42. https://doi.org/10.1302/0301-620X.79B1.0790036

12. Biau DJ, Pannier S, Masquelet AC, Glorion C. Case report: reconstruction of a 16-cm diaphyseal defect after Ewing's resection in a child. Clin Orthop Relat Res 2009;467:572-577. https://doi.org/10.1007/s11999-008-0605-9

13. Ozaki T, Hillmann A, Bettin D, Wuisman P, Winkelmann W. Intramedullary, antibiotic-loaded cemented, massive allografts for skeletal reconstruction 26 cases compared with 19 uncemented allografts. Acta Orthop Scand 1997;68:387-391. https://doi.org/10.3109/17453679708996183 